\title{
Modelos de erro de rastreamento para carteiras de investimento
}

\author{
Estela M. Oliveira Oswaldo L.V. Costa \\ Escola Politécnica, Universidade de São Paulo \\ Av. Prof. Luciano Gualberto, Butantã, São Paulo, Brasil \\ E-mail: oswaldo@lac.usp, estelaime@hotmail.com
}

\section{$\underline{\text { RESUMO }}$}

Modelos de erro de rastreamento são estratégias utilizadas pelos administradores de carteiras de investimento que visam montar portfólios para seguir algum índice de referência (benchmark) $[1,4]$, utilizando apenas alguns ativos (geralmente os que possuem maior liquidez) que compõem a carteira de referência. Denomina-se nesses casos de erro de rastreamento a diferença entre o retorno da carteira que se deseja montar e o retorno da carteira de referência. O objetivo destes modelos é obter uma carteira que minimiza a variância do erro de rastreamento (TEV) para um excesso de retorno esperado fixado. Da mesma forma que nos modelos de média variância tradicionais $[2,3,5]$ nestes problemas de otimização para o TEV a diversificação dos ativos, é fundamental para se alcançar o resultado esperado.

Neste trabalho foram implementados alguns modelos de rastreamento apresentados em $[1,4]$ considerando sete ativos com alto volume de negociação da Bolsa de Valores de São Paulo e o IBOVESPA como benchmark no período de 2008 a 2013. Com a estimativa dos retornos esperados e a matriz de covariância dos ativos considerados, obteve-se a carteira de rastreamento ótima de cada modelo.

A partir desses dados têm-se também as curvas parabólicas relacionando risco versus retorno, estabelecendo assim a fronteira eficiente para as carteiras de mínimo TEV. Em [4] mostra-se que se a carteira de referência não for eficiente as carteiras de mínimo TEV também não serão eficientes, e a curva da fronteira eficiente associada ao modelo de rastreamento terá um deslocamento fixo em relação à fronteira eficiente geral como em $[2,3]$.

Como uma tentativa para melhorar os resultados em [4], é apresentado em [1] um método de seleção de carteiras cujo objetivo é selecionar uma carteira a partir do conjunto de carteiras que têm TEV mínimo para vários níveis de um alfa ex-ante (alfa ex-ante é a diferença entre o excesso de retorno esperado de uma carteira e o excesso de retorno esperado da carteira de referência ajustada pelo seu beta, ver [1]). Neste trabalho os modelos propostos em [1] também serão considerados e comparados com os modelos propostos em [4], utilizando-se os dados do IBOVESPA de 2008 a 2013 e os 7 ativos mencionados anteriormente.

Palavras-chave: Otimização, risco, retorno, modelos matemáticos e erro de rastreamento de investimento financeiro.

\section{Referências}

[1] Alexander, G. J., e Baptista, A. M. (2010). Active portfolio management with benchmarking A frontier based on alpha. Journal of Banking and Finance, 34(9), $2185-2197$. 
[2] Markowitz, H. M. (1952). Portfolio Selection. Journal of Finance, 7, 77-91.

[3] Markowitz, H. M. (1959). Portfolio Selection Efficient Diversification of Investments, Nova York, John Wiley.

[4] Roll, R. (1992). A mean/variance analysis of tracking error. The Journal of Portfolio Management,18, 13-22.

[5] Sharpe, W. The capital asset prices: A theory of market equilibrium under conditions of risk. Journal of Finance, 19, 425-442, 1964. 